\title{
Plasma phylloquinone, menaquinone-4 and menaquinone-7 levels and coronary artery calcification
}

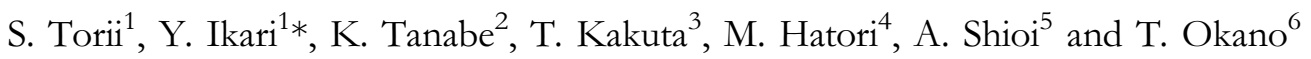 \\ ${ }^{1}$ Department of Cardiovascular Medicine, Tokai University School of Medicine, Isehara, Japan \\ ${ }^{2}$ Division of Cardiology, Mitsui Memorial Hospital, Tokyo, Japan \\ ${ }^{3}$ Division of Nephrology, Endocrinology, and Metabolism, Tokai University School of Medicine, Isehara, Japan \\ ${ }^{4}$ Department of Cardiology, Ibaraki Seinan Medical Center Hospital, Ibaraki, Japan \\ ${ }^{5}$ Department of Cardiovascular Medicine, Osaka City University Graduate School of Medicine, Osaka, Japan \\ ${ }^{6}$ Department of Hygienic Sciences, Kobe Pharmaceutical University, Kobe, Japan
}

(Received 17 November 2015 - Final revision received 17 April 2016 - Accepted 11 May 2016)

Journal of Nutritional Science (2016), vol. 5, e48, page 1 of 6

doi:10.1017/jns.2016.20

\section{Abstract}

Vitamin $\mathrm{K}$ is considered to be involved in the pathological mechanisms of coronary artery calcification (CAC). Correlation between CAC and plasma vitamin K levels was studied. A total of 103 patients, with at least one coronary risk factor, were studied. CAC was measured using 64-slice multislice computed tomography (MSCT) and divided into three groups: none (CAC score $=0 ; n$ 25), mild to moderate $(0<$ CAC score $<400 ; n$ 52) and severe $(\mathrm{CAC}$ score $>400 ; n$ 26). Phylloquinone (PK) and menaquinone (MK)-4 and MK-7 were measured by HPLC-tandem MS. Mean age of patients was 64 (sD 13) years, of which $57 \%$ were male. Median CAC score was $57 \cdot 2$. Median levels of PK, MK-4 and MK-7 were $1.33,0$ and $6.99 \mathrm{ng} / \mathrm{ml}$, showing that MK-7 was the dominant vitamin $\mathrm{K}$ in this population. MK-7 showed a significant inverse correlation with uncarboxylated osteocalcin (ucOC, $P=$ $0 \cdot 014)$, protein induced by vitamin $\mathrm{K}$ absence of antagonist-2 (PIVKA-2, $P=0 \cdot 013$ ), intact parathyroid hormone $(P=0 \cdot 007)$ and bone-specific alkaline phosphatase $(P=0 \cdot 018)$. CAC showed an inverse correlation with total circulating uncarboxylated matrix Gla protein $(\mathrm{t}-\mathrm{ucMGP}, P=0 \cdot 018)$ and $\mathrm{Hb}(P=$ $0 \cdot 05)$, and a positive correlation with age $(P<0 \cdot 001)$, creatinine, collagen type 1 cross-linked $\mathrm{N}$-terminal telopeptide $(\mathrm{NTX}, P=0 \cdot 03)$, pulse wave velocity $(P<0.001)$ and osteoprotegerin $(P<0 \cdot 001)$. However, CAC did not have a significant correlation with plasma levels of PK, MK-4 or MK-7. In conclusion, plasma MK-7, MK-4 or PK level did not show significant correlation with CAC despite the association between plasma vitamin $\mathrm{K}$ levels and vitamin $\mathrm{K}$ dependent proteins such as ucOC or PIVKA-2.

\section{Key words: Vitamin K: Coronary artery calcification: Osteocalcin: Matrix Gla protein}

Vitamin $\mathrm{K}$ is a cofactor for the enzyme responsible for the conversion of specific glutamyl residues to $\gamma$-carboxyglutamyl residues in several blood coagulation factors, bone-related proteins and other molecules. Vitamin $\mathrm{K}$ naturally exists in two forms, namely vitamin $\mathrm{K}_{1}$, also called phylloquinone (PK), and a group designated vitamin $K_{2}$, also known as menaquinones (MK). PK is widely distributed in green and leafy vegetables, whereas $\mathrm{MK}$ exist preferentially in meats (MK-4), eggs (MK-4), curd (MK-8, MK-9), cheese (MK-8, MK-9) and fermented soyabeans (MK-7). PK is endogenously converted to $\mathrm{MK}-4^{(1)}$.

Arterial calcification is a pathological change found in atherosclerosis but the mechanisms involved have not yet been defined. In mice, gene knockout of the matrix Gla protein

Abbreviations: BAP, bone-specific alkaline phosphatase; CAC, coronary artery calcification; MGP, matrix Gla protein; MK, menaquinone; NTX, N-terminal telopeptide; OC, osteocalcin; OPG, osteoprotegerin; PIVKA-2, protein induced by vitamin K absence of antagonist-2; PK, phylloquinone; PTH, parathyroid hormone; PWV, pulse wave velocity; t-ucMGP, total circulating uncarboxylated matrix Gla protein; ucOC, uncarboxylated osteocalcin.

* Corresponding author: Y. Ikari, fax +81 46393 6679, email ikari@is.icc.u-tokai.ac.jp 
Table 1. Patient characteristics (Number of subjects and percentages; mean values and standard deviations)

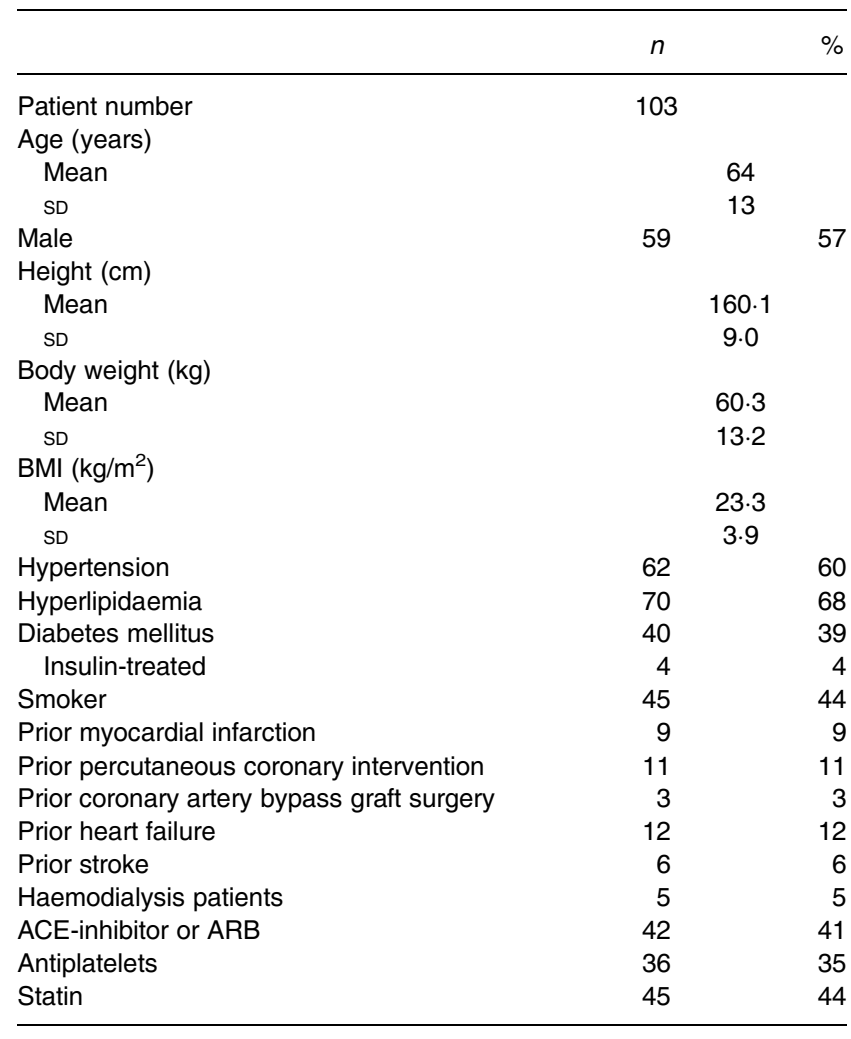

$\mathrm{ACE}$, angiotensin converting enzyme; ARB, angiotensin receptor blocker.

(MGP) caused death due to severe aortic calcification and aortic dissection $^{(2)}$. In humans the level of inactive MGP correlated with the risk of CVD and mortality ${ }^{(3-5)}$.

The vitamin $\mathrm{K}$ antagonist, warfarin, induces arterial calcification in animals which can be reversed by the addition of $\mathrm{MK}^{(6)}$. A similar relationship between warfarin and arterial calcification has also been observed clinically ${ }^{(7)}$. Warfarin is a drug that blocks epoxide reductase, a recycling enzyme of vitamin K. Gene polymorphism of the epoxide reductase subunit correlated clinically with cardiovascular events such as stroke, myocardial infarction and aortic dissection ${ }^{(8)}$. A high dietary intake of PK as well as MK reduced coronary artery calcification $(\mathrm{CAC})^{(9,10)}$ and prevented cardiovascular events in women ${ }^{(11)}$.

We performed an observational study to test the association between CAC and plasma levels of PK, MK-4 and MK-7.

\section{Methods}

\section{Patient selection and study protocol}

This study, the Vitamin K2 Super Minimizing Mineralization Trial (K2 SUMMIT-1), was performed at three hospitals (Tokai University Hospital, Mitsui Memorial Hospital and Ibaraki Seinan Medical Center Hospital), between 1 May 2008 and 28 December 2012. Patients with at least one coronary risk factor, e.g. hypertension, diabetes mellitus, hypercholesterolaemia, smoking, and a family history of coronary artery disease, were enrolled. Exclusion criteria were patients with an implanted coronary stent or pacemaker. The Institutional Review Board approved the study and all patients gave written informed consent. A medical history that included prior myocardial infarction, prior percutaneous coronary intervention, prior coronary artery bypass graft surgery, prior heart failure, prior stroke, or haemodialysis was obtained from each patient. The correlation between a CAC score and each coronary risk factor was studied.

\section{Cardiac multi-slice computed tomography data acquisition and analysis}

A prospective non-enhanced coronary Ca scan was performed with a 64-slice MSCT scanner (Siemens) in all patients. For quantitative assessment of CAC, the Agatston score ${ }^{(12)}$ was calculated, using a $3 \mathrm{~mm}$ CT slice thickness and a detection threshold of 130 Hounsfield units (HU) involving $\geqq 1 \mathrm{~mm}^{2}$ area/lesion (three pixels). A total CAC score was determined by summing individual lesion scores from each of four anatomical sites (left main trunk, left anterior descending artery, left circumflex artery, and right coronary artery $)^{(13)}$. Patients were divided into three groups according to the clinical grading of CAC level: (1) none (Agatston score $=0)$; (2) mild to moderate CAC $(0<$ Agatston score < 400); and (3) severe CAC (Agatston score > 400).

\section{Measurements}

Plasma was obtained from patients in the morning after overnight fasting and stored at $-30^{\circ} \mathrm{C}$. Vitamin $\mathrm{K}$ (PK, MK-4 and MK-7) was determined by HPLC-tandem MS with atmospheric pressure chemical ionisation (LC-APCI-MS/MS) as described previously ${ }^{(14)}$.

Total circulating uncarboxylated MGP (t-ucMGP) measurements were performed by Dr Cees Vermeer's group (Cardiovascular Research Center, Maastricht University, the Netherlands). Measurement methods and measurement errors have been reported previously ${ }^{(15)}$. Intact parathyroid hormone (PTH), osteocalcin (OC), uncarboxylated OC (ucOC), collagen type 1 cross-linked N-terminal telopeptide (NTX), bonespecific alkaline phosphatase (BAP), high sensitive C-reactive protein, intact $\mathrm{PTH}$, oxidised LDL and protein induced by vitamin $\mathrm{K}$ absence of antagonist 2 (PIVKA-2) were measured by SRL Inc. Intra- and inter-assay CV were OC $(3.4 \%$, $5.0 \%)$, ucOC $(1.3 \%, 2.0 \%)$, NTX $(8.8 \%, 11.9 \%)$, BAP $(2.5 \%, 2.9 \%)$, high sensitive C-reactive protein $(0.9 \%$, $2.3 \%)$, intact PTH $(0.8 \%, 3.0 \%)$, oxidised LDL (6.2\%, $5.3 \%)$, osteoprotegerin (OPG) $(3.0 \%, 5.0 \%)$ and PIVKA$2(5.7 \%, 6.1 \%)$.

Bone density was measured in the lumbar vertebra using a bone densitometer (DSC-900FX; Hitachi-Aloka Medical).

Ankle-brachial index and brachial-ankle pulse wave velocity (PWV) were measured using a vascular screening device (BP-203 RPE; Omron-Colin).

\section{Statistics}

Continuous variables are presented as means and standard deviations in a normal distribution or as medians and 
Table 2. Baseline blood test, calcification score and pulse wave velocity (Mean values and standard deviations)

\begin{tabular}{|c|c|c|}
\hline & Mean & SD \\
\hline $\mathrm{Hb}(\mathrm{g} / \mathrm{l})$ & 136 & 17 \\
\hline Prothrombin time (international normalised ratio) & 0.93 & 0.08 \\
\hline Albumin $(g / l)$ & $42 \cdot 4$ & $2 \cdot 7$ \\
\hline TAG ( $\mathrm{mmol} / \mathrm{l})$ & 1.66 & $1 \cdot 20$ \\
\hline Alkaline phosphatase (IU/I) & $231 \cdot 1$ & 69.9 \\
\hline Estimated GFR( $\mathrm{ml} / \mathrm{min}$ per $\left.1.73 \mathrm{~m}^{2}\right)$ & $60 \cdot 4$ & $25 \cdot 7$ \\
\hline Phosphate $(\mathrm{mmol} / \mathrm{l})$ & $1 \cdot 16$ & 0.36 \\
\hline $\mathrm{Ca}(\mathrm{mmol} / \mathrm{l})$ & $2 \cdot 28$ & 0.23 \\
\hline ucOC (ng/ml) & $5 \cdot 8$ & 11.9 \\
\hline $\mathrm{OC}(\mathrm{ng} / \mathrm{ml})$ & $8 \cdot 9$ & $16 \cdot 0$ \\
\hline ucOC:OC ratio & 0.73 & 0.96 \\
\hline PIVKA-2 (mAU/ml) & 23.9 & $11 \cdot 1$ \\
\hline Intact parathyroid hormone (pg/ml) & $55 \cdot 0$ & 82.5 \\
\hline Bone-specific alkaline phosphatase ( $\mu \mathrm{g} / \mathrm{l})$ & $17 \cdot 7$ & $9 \cdot 1$ \\
\hline NTX (nmol BCE/l) & $18 \cdot 6$ & 13.5 \\
\hline hsCRP (mg/l) & 1320 & 3707 \\
\hline Osteoprotegerin (ng/ml) & 101.4 & 60.5 \\
\hline Oxidised LDL $(\mu \mathrm{mol} / \mathrm{l})$ & 3.00 & 1.35 \\
\hline t-ucMGP (nmol/l) & 3315 & 1688 \\
\hline Phylloquinone (ng/ml) & 1.6 & $1 \cdot 3$ \\
\hline Menaquinone-7 (ng/ml) & $10 \cdot 1$ & $10 \cdot 3$ \\
\hline Menaquinone-4 (ng/ml) & $2 \cdot 1$ & 15.9 \\
\hline Coronary artery Ca score (U) & 591 & 1532 \\
\hline Bone density $\left(\mathrm{g} / \mathrm{cm}^{2}\right)$ & 0.99 & 0.25 \\
\hline$\%$ Bone density & 106.5 & $21 \cdot 1$ \\
\hline $\mathrm{ABI}$ & 1.14 & 0.11 \\
\hline $\mathrm{PWV}(\mathrm{cm} / \mathrm{s})$ & 1682 & 395 \\
\hline
\end{tabular}

IU, international units; GFR, glomerular filtration rate; ucOC, uncarboxylated osteocalcin; OC, osteocalcin; PIVKA-2, protein induced by vitamin $\mathrm{K}$ absence or antagonist- 2; mAU, milli absorbance units; NTX, N-terminal telopeptide; BCE, bone collagen equivalents; hsCRP, high sensitive C-reactive protein; t-ucMGP, total circulating uncarboxylated matrix Gla protein; $\mathrm{ABI}$, ankle-brachial index; PWV, pulse wave velocity.

interquartile ranges. Categorical variables are presented as absolute numbers and percentages. Univariate analysis was performed to assess the relationship between CAC and other parameters by calculating Spearman's rank correlation coefficients. To identify the primary predictor for CAC, ANOVA was performed. Statistical analysis was performed using SAS version 9.2 (SAS Institute, Inc.).

This study was registered as UMIN000002759.

\section{Results}

Baseline patient characteristics are shown in Table 1. The mean age of the study population was 64 (SD 13) years, of which $57 \%$ were male. Five patients $(4.9 \%)$ received haemodialysis. Pathology results for CAC, bone density, ankle-brachial index and PWV are shown in Table 2. The median value of the total $\mathrm{Ca}$ score was $57 \cdot 2$.

Plasma levels of PK, MK-4 and MK-7 are shown in Fig. 1. Statistical analysis showed that PK, MK-4 and MK-7 were normally distributed as 1.64 (SD 1.26) ng/ml (median 1.33 $\mathrm{ng} / \mathrm{ml}$ ), $2 \cdot 1$ (SD 15.9$) \mathrm{ng} / \mathrm{ml}$ (median 0 , interquartile range 0-0.04, maximum $157 \cdot 6 \mathrm{ng} / \mathrm{ml}$ ) and $10 \cdot 1$ (sD10.3) $\mathrm{ng} / \mathrm{ml}$ (median $6.99 \mathrm{ng} / \mathrm{ml}$ ).

Associations between coronary calcification severity and risk factors are shown in Table 3. Patients with severe calcification were significantly older, and were significantly more likely to
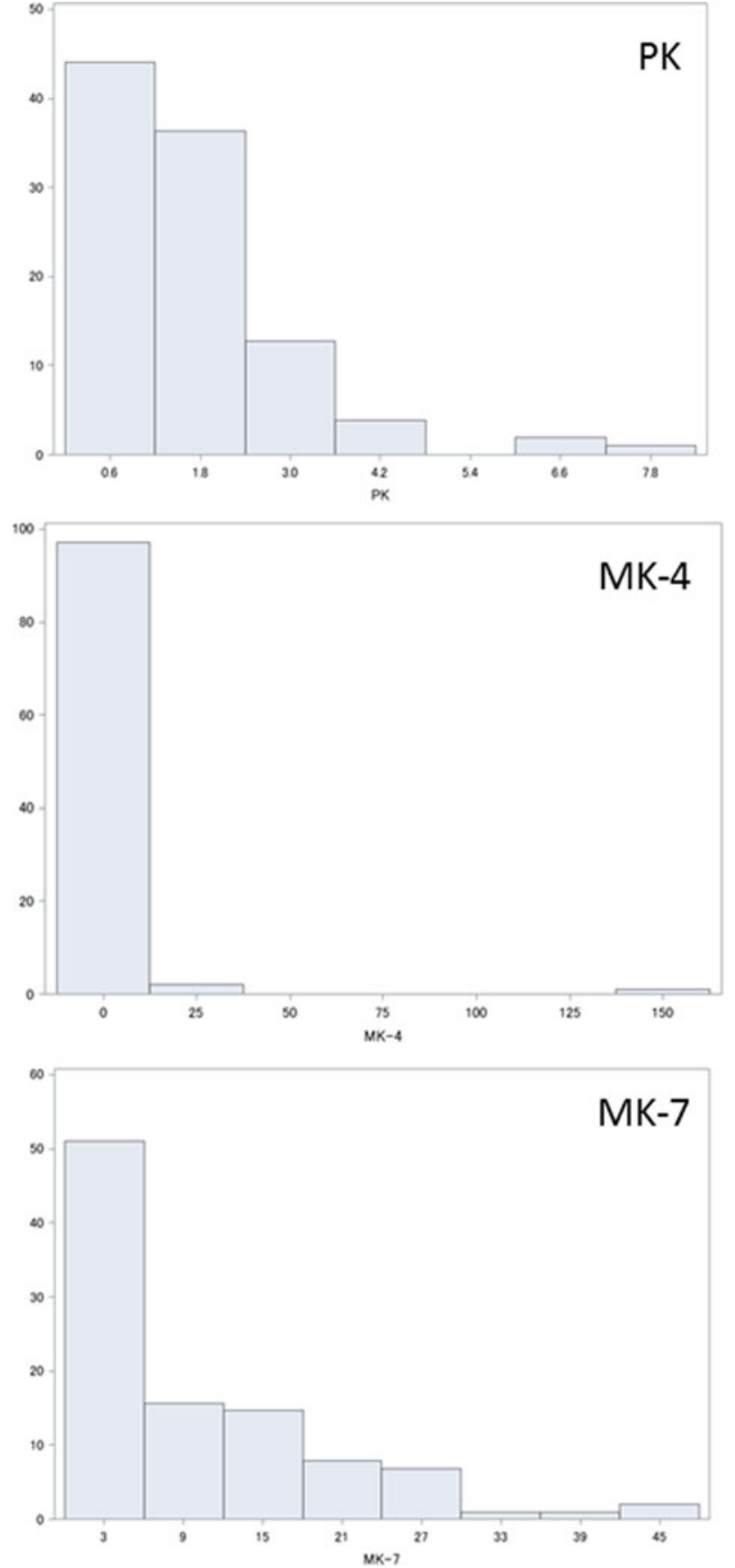

Fig. 1. Histograms showing distribution (\%) of plasma vitamin $\mathrm{K}$ levels ( $\mathrm{ng} / \mathrm{ml}$ ): (a) phylloquinone (PK); (b) menaquinone (MK)-4; (c) MK-7.

have a history of myocardial infarction, stroke or peripheral artery disease. Such patients showed significantly lower Hb levels and poor kidney function; they had significantly higher levels of NTX, OPG and ucOC, and a lower level of t-ucMGP. Patients with severe calcification also had significantly higher PWV values. However, plasma levels of PK, MK-4 or MK-7 did not correlate with the severity of CAC.

MK-7, PK, TAG-adjusted MK-7 and TAG-adjusted PK data and related factors are listed in Table 4. MK-7 was inversely correlated with ucOC, PIVKA-2, creatinine, intact PTH, BAP and NTX, but positively correlated with percentage bone density in a statistically significant manner. 
Table 3. Association between the severity of coronary calcification and clinical or blood test factors (Mean values and standard deviations, or percentages)

\begin{tabular}{|c|c|c|c|c|c|c|c|}
\hline & \multicolumn{2}{|c|}{$\begin{array}{l}\text { No Ca }(n 25) \text { : } \\
\text { Ca score }=0\end{array}$} & \multicolumn{2}{|c|}{$\begin{array}{c}\text { Mild to moderate Ca } \\
(n 52): 0<\text { Ca score }<400\end{array}$} & \multicolumn{2}{|c|}{$\begin{array}{l}\text { Severe Ca }(n 26) \text { : } \\
\text { Ca score }>400\end{array}$} & \multirow[b]{2}{*}{$P$} \\
\hline & Mean & SD & Mean & SD & Mean & SD & \\
\hline Age (years) & 56 & 14 & 65 & 11 & 71 & 12 & $<0.001$ \\
\hline History of Ml (\%) & \multicolumn{2}{|c|}{0} & \multicolumn{2}{|c|}{8} & \multicolumn{2}{|c|}{19} & 0.048 \\
\hline History of stroke (\%) & \multicolumn{2}{|c|}{0} & \multicolumn{2}{|c|}{4} & \multicolumn{2}{|c|}{15} & 0.05 \\
\hline Peripheral artery disease (\%) & \multicolumn{2}{|c|}{0} & \multicolumn{2}{|c|}{2} & \multicolumn{2}{|c|}{12} & 0.06 \\
\hline Use of aspirin (\%) & \multicolumn{2}{|c|}{12} & \multicolumn{2}{|c|}{31} & \multicolumn{2}{|c|}{46} & 0.03 \\
\hline Haemodialysis (\%) & \multicolumn{2}{|c|}{4} & \multicolumn{2}{|c|}{2} & \multicolumn{2}{|c|}{15} & 0.05 \\
\hline $\mathrm{Hb}(\mathrm{g} / \mathrm{l})$ & 141 & 18 & 137 & 14 & 129 & 19 & 0.03 \\
\hline BMI $\left(\mathrm{kg} / \mathrm{m}^{2}\right)$ & 24.4 & 4.0 & $24 \cdot 0$ & $4 \cdot 2$ & $21 \cdot 2$ & 1.3 & 0.004 \\
\hline Albumin $(g / l)$ & 43 & 3 & 42 & 2 & 41 & 3 & 0.04 \\
\hline Creatinine $(\mu \mathrm{mol} / \mathrm{l})$ & 124 & 230 & 80 & 88 & 239 & 398 & 0.03 \\
\hline $\mathrm{Ca}(\mathrm{mmol} / \mathrm{l})$ & $2 \cdot 3$ & 0.3 & $2 \cdot 3$ & 0.2 & $2 \cdot 3$ & 0.1 & 0.94 \\
\hline Phosphate (mmol/l) & $1 \cdot 2$ & 0.5 & 1.1 & 0.3 & $1 \cdot 2$ & 0.3 & 0.94 \\
\hline ALP $(I U / I)$ & 258 & 78 & 213 & 49 & 242 & 88 & 0.02 \\
\hline Bone type ALP $(\mu \mathrm{g} / \mathrm{l})$ & $16 \cdot 1$ & $7 \cdot 8$ & $17 \cdot 2$ & $7 \cdot 2$ & $20 \cdot 3$ & $12 \cdot 9$ & 0.23 \\
\hline Intact PTH (pg/ml) & 52 & 58 & 41 & 21 & 85 & 148 & 0.09 \\
\hline Oxidised LDL (mmol/l) & 3.2 & 1.6 & 3.1 & 1.4 & $2 \cdot 7$ & 0.9 & 0.32 \\
\hline NTX (nmol BCE/l) & 16 & 6 & 17 & 11 & 25 & 11 & 0.03 \\
\hline $\mathrm{OPG}(\mathrm{ng} / \mathrm{ml})$ & 85 & 36 & 85 & 38 & 150 & 86 & $<0.001$ \\
\hline t-ucMGP (nmol/l) & 3455 & 1508 & 3659 & 1843 & 2529 & 1292 & 0.018 \\
\hline $\mathrm{ucOC}(\mathrm{ng} / \mathrm{ml})$ & 4.6 & 3.6 & 4.0 & 3.8 & $10 \cdot 7$ & 22.5 & 0.056 \\
\hline PIVKA-2 (mAU/ml) & $21 \cdot 6$ & $5 \cdot 3$ & $23 \cdot 8$ & $8 \cdot 1$ & $26 \cdot 1$ & $18 \cdot 1$ & 0.36 \\
\hline PK (ng/ml) & 1.4 & 1.0 & 1.8 & 1.3 & 1.6 & 1.3 & 0.46 \\
\hline MK-4 (ng/ml) & $6 \cdot 3$ & 31.5 & 0.94 & 4.8 & 0.39 & 1.9 & 0.31 \\
\hline MK-7 (ng/ml) & 8.7 & 9.1 & 10.5 & $10 \cdot 1$ & $10 \cdot 8$ & 11.1 & 0.72 \\
\hline hsCRP (mg/l) & 2984 & 7169 & 918 & 1076 & 523 & 448 & 0.03 \\
\hline Bone matrix $\left(\mathrm{g} / \mathrm{cm}^{2}\right)$ & 1.07 & 0.23 & 0.99 & 0.23 & 0.95 & 0.31 & 0.22 \\
\hline $\mathrm{ABI}$ & $1 \cdot 2$ & 0.1 & $1 \cdot 2$ & 0.1 & $1 \cdot 1$ & 0.2 & 0.18 \\
\hline ba-PWV (cm/s) & 1424 & 321 & 1655 & 281 & 2007 & 453 & $<0.001$ \\
\hline
\end{tabular}

MI, myocardial infarction; ALP, alkaline phosphatase; PTH, parathyroid hormone; BCE, bone collagen equivalents; NTX, N-terminal telopeptide; OPG, osteoprotegerin; t-ucMGP, total circulating uncarboxylated matrix Gla protein; ucOC, uncarboxylated osteocalcin; PIVKA-2, protein induced by vitamin $\mathrm{K}$ absence or antagonist-2; mAU, milli absorbance units; PK, phylloquinone; MK, menaquinone; hsCRP, high sensitive C-reactive protein; $A B I$, ankle-brachial index; ba-PWV, brachial-ankle pulse wave velocity.

\section{Discussion}

In the studied population, MK-7 was the dominant vitamin $\mathrm{K}$ which had inverse correlation with ucOC, PIVKA-2, intact PTH and BAP. CAC showed an inverse correlation with t-ucMGP and $\mathrm{Hb}$, and a positive correlation with age, creatinine, NTX, PWV and OPG. However, CAC did not have a significant correlation with plasma levels of PK, MK-4 or MK-7.

In this study, the medians of PK, MK-4 and MK-7 were found to be $1.33,0$ and $6.99 \mathrm{ng} / \mathrm{ml}$, respectively, with levels of PK and MK-4 similar to those of previous reports ${ }^{(16,17)}$. On the other hand, the plasma MK-7 level was higher than those of previous reports: a median of $1.43 \mathrm{ng} / \mathrm{ml}$ was found by Fusaro et al. and a median of $3.92 \mathrm{ng} / \mathrm{ml}$ by Tsugawa et al. ${ }^{(16,17)}$. Such a discrepancy with the published literature may probably exist because this study was conducted in eastern Japan where fermented soyabeans known as natto, a food rich in MK-7, is popular. Tsugawa et al. reported that $\mathrm{PK}$ and $\mathrm{MK}-7$, but not MK-4, correlated inversely with $\mathrm{ucOC}^{(17)}$. In comparison, we observed that MK-7, but not PK or MK-4, correlated inversely with ucOC and suggest this was because MK-7 may be the dominant vitamin $\mathrm{K}$ in this studied population. The population with the highest tertile of MK-7 exhibited a high percentage bone density, and low levels of ucOC, PIVKA-2, intact PTH, BAP and NTX.
These data suggest that a high intake of $\mathrm{MK}-7$ induced carboxylation to reduce ucOC and PIVKA-2, and to increase bone density with reduced bone destruction.

The group showing severe CAC were older in age, had a high PWV, and a frequent history of myocardial infarction, stroke and peripheral artery disease, indicating severe, wholebody atherosclerosis. As CAC is one of the known forms of atherosclerosis, such a relationship is conceivable ${ }^{(18,19)}$. Furthermore, the group with severe CAC also displayed chronic kidney disease and mineral and bone disorders, as suggested by high creatinine, low $\mathrm{Hb}$ and high NTX levels. Chronic kidney disease is also a well-known risk factor for $\mathrm{CAC}^{(20,21)}$ as also confirmed in this study.

CAC was also related to high levels of OPG, and low levels of t-ucMGP; these were also previously reported risk factors for arterial calcification ${ }^{(2,3,22-24)}$. The inverse association between t-ucMGP and calcification is generally explained by the tight binding of MGP's phosphoserine residues to hydroxyapatite, initially reported by Price et al. ${ }^{(25)}$. Despite the inverse correlation between $\mathrm{MK}-7$ and $\mathrm{ucOC}$, we remained puzzled as to the absence of a direct correlation between CAC and plasma vitamin $\mathrm{K}$ levels. The plasma vitamin $\mathrm{K}$ level reflects food intake over a short period of time but the ucOC level reflects a longer period of vitamin $\mathrm{K}$ insufficiency. Time-series studies in which the ucOC level was lowered by 
Table 4. Plasma levels of vitamin $\mathrm{K}$ and related factors

(Mean values and standard deviations, or medians and ranges)

\begin{tabular}{|c|c|c|c|c|c|c|c|}
\hline & \multicolumn{2}{|c|}{ Low } & \multicolumn{2}{|c|}{ Medium } & \multicolumn{2}{|c|}{ High } & \multirow[b]{2}{*}{$P$} \\
\hline & Mean & SD & Mean & SD & Mean & SD & \\
\hline \multicolumn{8}{|l|}{ MK-7 tertile group } \\
\hline$n$ & \multicolumn{2}{|c|}{34} & \multicolumn{2}{|c|}{34} & \multicolumn{2}{|c|}{35} & \\
\hline \multicolumn{8}{|l|}{ MK-7 (ng/ml) } \\
\hline Median & \multicolumn{2}{|c|}{1.28} & \multicolumn{2}{|c|}{5.74} & \multicolumn{2}{|c|}{20.9} & \\
\hline Range & \multicolumn{2}{|c|}{$0-3 \cdot 12$} & \multicolumn{2}{|c|}{$3 \cdot 12-11 \cdot 8$} & \multicolumn{2}{|c|}{$11 \cdot 8-46 \cdot 4$} & \\
\hline Creatinine $(\mu \mathrm{mol} / \mathrm{l})$ & 221 & 371 & 80 & 62 & 97 & 71 & 0.0241 \\
\hline$\%$ Bone density & 103 & 21 & 103 & 17 & 113 & 23 & 0.0565 \\
\hline ucOC (ng/ml) & $10 \cdot 8$ & $20 \cdot 2$ & 4.2 & 3.4 & 2.9 & 1.6 & 0.0149 \\
\hline PIVKA-2 (mAU/ml) & 28.6 & $16 \cdot 6$ & 22.5 & 5.7 & $21 \cdot 0$ & $7 \cdot 0$ & 0.0133 \\
\hline Intact PTH (pg/ml) & $89 \cdot 3$ & 135.5 & 46.6 & $15 \cdot 6$ & 29.9 & 21.5 & 0.0077 \\
\hline BAP $(\mu \mathrm{g} / \mathrm{l})$ & $21 \cdot 2$ & $12 \cdot 0$ & $16 \cdot 8$ & $6 \cdot 1$ & $15 \cdot 3$ & 7.5 & 0.0188 \\
\hline NTX (nmol BCE/l) & 23.4 & $21 \cdot 6$ & $16 \cdot 6$ & $5 \cdot 3$ & $15 \cdot 8$ & $5 \cdot 6$ & 0.0342 \\
\hline \multicolumn{8}{|l|}{ MK-7/TAG tertile group } \\
\hline$n$ & \multicolumn{2}{|c|}{35} & \multicolumn{2}{|c|}{33} & \multicolumn{2}{|c|}{35} & \\
\hline \multicolumn{8}{|c|}{ MK-7/TAG (ng/ml per mmol) } \\
\hline Median & \multirow{2}{*}{\multicolumn{2}{|c|}{$\begin{array}{c}0.011 \\
0-0.031\end{array}$}} & \multicolumn{2}{|c|}{0.045} & \multicolumn{2}{|c|}{0.161} & \\
\hline Range & & & & & & & \\
\hline ucOC (ng/ml) & 11.2 & $20 \cdot 2$ & 3.6 & $2 \cdot 4$ & 3.0 & $2 \cdot 3$ & 0.0080 \\
\hline PIVKA-2 (mAU/ml) & 28.9 & $16 \cdot 5$ & $21 \cdot 8$ & 5.5 & $21 \cdot 3$ & $7 \cdot 2$ & 0.0077 \\
\hline Intact PTH (pg/ml) & 89.4 & $132 \cdot 6$ & $42 \cdot 8$ & $21 \cdot 2$ & $32 \cdot 1$ & $22 \cdot 3$ & 0.0074 \\
\hline BAP $(\mu \mathrm{g} / \mathrm{l})$ & 21.5 & 11.9 & $15 \cdot 6$ & 5.9 & $15 \cdot 9$ & 7.4 & 0.0089 \\
\hline \multicolumn{8}{|l|}{ PK tertile group } \\
\hline$n$ & \multicolumn{2}{|c|}{34} & & & & & \\
\hline PK (ng/ml) & & & & & & & \\
\hline Median & & & & & & & \\
\hline Range & & & & & & & \\
\hline $\mathrm{Hb}(\mathrm{g} / \mathrm{l})$ & 131 & 19 & 136 & 14 & 141 & 16 & 0.0249 \\
\hline TAG (mmol/l) & 1.3 & 0.9 & 1.8 & 0.8 & 1.8 & 0.7 & 0.0094 \\
\hline BAP $(\mu \mathrm{g} / \mathrm{l})$ & $22 \cdot 2$ & 11.6 & 15.5 & $7 \cdot 1$ & $15 \cdot 6$ & $6 \cdot 3$ & 0.0020 \\
\hline PK/TAG tertile group & & & & & & & \\
\hline$n$ & & & & & & & \\
\hline PK/TAG $(\mathrm{ng} / \mathrm{ml}$ per $\mathrm{mm}$ & & & & & & & \\
\hline Median & & & & & & & \\
\hline Range & & & & & 0.0 & & \\
\hline Age (years) & 61 & 13 & 61 & 15 & 70 & 8 & 0.0014 \\
\hline TAG $(\mathrm{mmol} / \mathrm{l})$ & $2 \cdot 4$ & 1.6 & 1.5 & 0.7 & $1 \cdot 1$ & 0.6 & $<0.0001$ \\
\hline BAP $(\mu \mathrm{g} / \mathrm{l})$ & $21 \cdot 1$ & 11.2 & $15 \cdot 2$ & 6.4 & $16 \cdot 8$ & 8.2 & 0.0192 \\
\hline Oxidised LDL (mmol/l) & 3.4 & 1.5 & 2.9 & 1.4 & $2 \cdot 6$ & 0.9 & 0.0320 \\
\hline
\end{tabular}

MK, menaquinone; ucOC, uncarboxylated osteocalcin; PIVKA-2, protein induced by vitamin K absence or antagonist-2; mAU, milli absorbance units; PTH, parathyroid hormone; $\mathrm{BCE}$, bone collagen equivalents; BAP, bone-specific alkaline phosphatase; NTX, N-terminal telopeptide; PK, phylloquinone.

vitamin $\mathrm{K}$ supplementation showed that it remained unchanged at $15 \mathrm{~d}$, but, by $30 \mathrm{~d}$, reduction was observed ${ }^{(26-28)}$. Despite a weak association between CAC and ucOC $(P=$ 0.056), CAC may correlate with the chronic status of vitamin $\mathrm{K}$, but not with the plasma vitamin $\mathrm{K}$ level shown by a single measurement.

There are several limitations to this study. First, this study was conducted in eastern Japan where fermented soyabeans (natto) are a popular food, thus making the observed plasma MK-7 level higher than in previous studies. Second, as measurements of plasma vitamin $\mathrm{K}$ levels were not repeatedly performed, the possibility remains that errors were caused by the ingestion, by patients, of varying food content. Third, the number of patients studied was limited. If patient numbers were increased, a direct correlation between plasma vitamin $\mathrm{K}$ levels and CAC may be more readily observed. Finally, we did not measure dephospho-uncarboxylated
MGP which is the most sensitive vitamin $\mathrm{K}$ marker presently available, and also a risk marker for CVD and mortality.

In conclusion, we could not show a direct correlation between plasma vitamin $\mathrm{K}$ levels and CAC. However, CAC correlated with markers of chronic insufficiency of vitamin $\mathrm{K}$ such as ucOC. This suggests that the chronic intake of sufficient vitamin $\mathrm{K}$ may have an inhibitory effect on CAC.

\section{Acknowledgements}

We thank Cees Vermeer for measuring t-ucMGP. This study was supported by the Eizai Pharmaceutical Company. We also thank Sanko-Junyaku for help in the measurement of plasma factors.

The contribution of the authors was as follows: concept and design: Y. I. and A. S.; analysis and interpretation of data: S. T., 
Y. I., A. S. and T. O.; recruitment of patients: S. T., Y. I., K. T., T. K. and M. H.; critical writing: S. T., Y. I., A. S. and T. O. There were no conflicts of interest.

\section{References}

1. Nakagawa K, Hirota Y, Sawada N, et al. (2010) Identification of UBIAD1 as a novel human menaquinone-4 biosynthetic enzyme. Nature 468, 117-121.

2. Luo G, Ducy P, McKee MD, et al. (1997) Spontaneous calcification of arteries and cartilage in mice lacking matrix GLA protein. Nature 386, 78-81.

3. Jono S, Ikari Y, Vermeer C, et al. (2004) Matrix Gla protein is associated with coronary artery calcification as assessed by electronbeam computed tomography. Thromb Haemost 91, 790-794.

4. Liu YP, Gu YM, Thijs L, et al. (2015) Inactive matrix Gla protein is causally related to adverse health outcomes: a Mendelian randomization study in a Flemish population. Hypertension 65, 463-470.

5. Mayer O Jr, Seidlerova J, Bruthans J, et al. (2014) Desphosphouncarboxylated matrix Gla-protein is associated with mortality risk in patients with chronic stable vascular disease. Atherosclerosis 235, 162-168.

6. Price PA, Faus SA \& Williamson MK (1998) Warfarin causes rapid calcification of the elastic lamellae in rat arteries and heart valves. Arterioscler Thromb V asc Biol 18, 1400-1407.

7. Koos R, Mahnken AH, Muhlenbruch G, et al. (2005) Relation of oral anticoagulation to cardiac valvular and coronary calcium assessed by multislice spiral computed tomography. Am J Cardiol 96, 747-749.

8. Wang Y, Zhang W, Zhang Y, et al. (2006) VKORC1 haplotypes are associated with arterial vascular diseases (stroke, coronary heart disease, and aortic dissection). Circulation 113, 1615-1621.

9. Beulens JW, Bots ML, Atsma F, et al. (2009) High dietary menaquinone intake is associated with reduced coronary calcification. Atherosclerosis 203, 489-493.

10. Shea MK \& Holden RM (2012) Vitamin K status and vascular calcification: evidence from observational and clinical studies. $A d v$ Nutr 3, 158-165.

11. Gast GC, de Roos NM, Sluijs I, et al. (2009) A high menaquinone intake reduces the incidence of coronary heart disease. Nutr Metab Cardiovasc Dis 19, 504-510.

12. Agatston AS, Janowitz WR, Hildner FJ, et al. (1990) Quantification of coronary artery calcium using ultrafast computed tomography. I Am Coll Cardiol 15, 827-832.

13. Budoff MJ, Achenbach S, Blumenthal RS, et al. (2006) Assessment of coronary artery disease by cardiac computed tomography: a scientific statement from the American Heart Association Committee on Cardiovascular Imaging and Intervention, Council on Cardiovascular Radiology and Intervention, and Committee on Cardiac Imaging, Council on Clinical Cardiology. Circulation 114, $1761-1791$
14. Suhara Y, Kamao M, Tsugawa N, et al. (2005) Method for the determination of vitamin $\mathrm{K}$ homologues in human plasma using highperformance liquid chromatography-tandem mass spectrometry. Anal Chem 77, 757-763.

15. Dalmeijer GW, van der Schouw YT, Vermeer C, et al. (2013) Circulating matrix Gla protein is associated with coronary artery calcification and vitamin $\mathrm{K}$ status in healthy women. J Nutr Biochem 24, 624-628.

16. Fusaro M, Noale M, Viola V, et al. (2012) Vitamin K, vertebral fractures, vascular calcifications, and mortality: VItamin K Italian (VIKI) dialysis study. J Bone Miner Res 27, 2271-2278.

17. Tsugawa N, Shiraki M, Suhara Y, et al. (2006) Vitamin K status of healthy Japanese women: age-related vitamin $\mathrm{K}$ requirement for $\gamma$-carboxylation of osteocalcin. Am J Clin Nutr 83, 380-386.

18. DeFilippis AP, Blaha MJ, Ndumele CE, et al. (2011) The association of Framingham and Reynolds risk scores with incidence and progression of coronary artery calcification in MESA (MultiEthnic Study of Atherosclerosis). J Am Coll Cardiol 58, 2076-2083.

19. Kronmal RA, McClelland RL, Detrano R, et al. (2007) Risk factors for the progression of coronary artery calcification in asymptomatic subjects: results from the Multi-Ethnic Study of Atherosclerosis (MESA). Circulation 115, 2722-2730.

20. Mehrotra R, Budoff M, Hokanson JE, et al. (2005) Progression of coronary artery calcification in diabetics with and without chronic kidney disease. Kidney Int 68, 1258-1266.

21. Kramer H, Toto R, Peshock R, et al. (2005) Association between chronic kidney disease and coronary artery calcification: the Dallas Heart Study. J Am Soc Nephrol 16, 507-513.

22. Okura T, Kurata M, Enomoto D, et al. (2010) Undercarboxylated osteocalcin is a biomarker of carotid calcification in patients with essential hypertension. Kidney Blood Press Res 33, 66-71.

23. Cranenburg EC, Brandenburg VM, Vermeer C, et al. (2009) Uncarboxylated matrix Gla protein (ucMGP) is associated with coronary artery calcification in haemodialysis patients. Thromb Haemost 101, 359-366.

24. Maser RE, Lenhard MJ, Sneider MB, et al. (2015) Osteoprotegerin is a better serum biomarker of coronary artery calcification than osteocalcin in type 2 diabetes. Endocr Pract 21, 14-22.

25. Price PA, Thomas GR, Pardini AW, et al. (2002) Discovery of a high molecular weight complex of calcium, phosphate, fetuin, and matrix $\gamma$-carboxyglutamic acid protein in the serum of etidronatetreated rats. J Biolog Chem 277, 3926-3934.

26. Nakamura E, Aoki M, Watanabe F, et al. (2014) Low-dose menaquinone-4 improves $\gamma$-carboxylation of osteocalcin in young males: a non-placebo-controlled dose-response study. Nutr J13, 85.

27. Binkley N, Harke J, Krueger D, et al. (2009) Vitamin K treatment reduces undercarboxylated osteocalcin but does not alter bone turnover, density, or geometry in healthy postmenopausal North American women. J Bone Miner Res 24, 983-991.

28. Theuwissen E, Cranenburg EC, Knapen MH, et al. (2012) Lowdose menaquinone-7 supplementation improved extra-hepatic vitamin $\mathrm{K}$ status, but had no effect on thrombin generation in healthy subjects. Br J Nutr 108, 1652-1657. 